\title{
Primary Fused Teeth and Findings in Permanent Dentition
}

\author{
Hatice Açıkel ${ }^{a}$ Sevgin İbiş ${ }^{b}$ Emine Şen Tunç ${ }^{a}$ \\ ${ }^{a}$ Department of Pediatric Dentistry, Faculty of Dentistry, University of Ondokuz Mayıs, Samsun, Turkey; \\ ${ }^{b}$ Samsun Training and Research Hospital, Samsun, Turkey
}

\section{Significance of the Study}

- In this study, primary fused teeth (PFT) were frequently observed in the mandibular anterior region. Caries formation and dental anomalies, especially permanent tooth aplasia, were often encountered in areas where PFT were seen. Hence, parents should be informed about possible dental problems associated with PFT and be encouraged to schedule regular follow-up appointments.

\section{Keywords}

Dental anomalies · Primary fused teeth · Pediatric dentistry

\begin{abstract}
Objective: The aim of this study was to investigate the characteristics of primary fused teeth (PFT) and their effect on permanent dentition in a group of Turkish children. Subjects and Methods: Dental records of 13,450 pediatric patients who attended the Pediatric Dental Clinic in northern Turkey between 2015 and 2017 were reviewed. Forty patients had been diagnosed with PFT and were included in the study. Clinical and radiographic examinations were conducted, and the distribution of PFT was calculated by type, sex, affected jaw, associated dental anomalies, and clinical complications. Data analysis involved descriptive statistics. Results: A total of 50 PFT were detected in the 40 patients. The mean age of patients was $6.7 \pm 0.3$ years (range $3-10$ years). The most common PFT were the mandibular lateral incisors and canines $(34,68 \%)$. The most prevalent type of PFT was type III $(20,40 \%)$. Of the 40 patients with PFT, 34 (85\%) also ex-
\end{abstract}

hibited other dental anomalies such as tooth aplasia, pegshaped incisors, talon cusps, ectopic eruption, and delayed eruption in both related and unrelated areas. The most common complications of PFT were fusion-related tooth aplasia ( $n=26[76 \%]$ ) and caries formation in the affected teeth (24 [48\%]). Conclusion: In this study, PFT were frequently observed in the mandibular anterior region. Caries formation and dental anomalies, especially permanent tooth aplasia, were often encountered in areas where PFT were seen. Hence, parents should be informed about possible dental problems associated with PFT and be encouraged to schedule regular follow-up appointments.

$$
\begin{aligned}
& \text { (c) } 2018 \text { The Author(s) } \\
& \text { Published by S. Karger AG, Basel }
\end{aligned}
$$

\section{Introduction}

The etiology of the fusion of teeth is not completely known; however, it is believed that it involves physical force or pressure from the follicles of adjacent teeth, hereditary conditions, and racial determinants $[1,2]$. The

\section{KARGER}

E-Mail karger@karger.com www.karger.com/mpp 
clinical appearance of the fusion depends on the developmental stage of the associated tooth buds. If contact between 2 dental buds occurs before the calcification phase, full fusion occurs, presenting clinically as a single large crown [3]. If the fusion takes place in the advanced stage of morph-differentiation, it may be limited to the roots, meaning the fused teeth might have separate pulp chambers and root canals $[3,4]$. Primary fused teeth (PFT) usually occur unilaterally $[5,6]$ and are more common in primary than in permanent dentition $[2,7,8]$. They nearly always occur in the anterior region, and most often involve the mandibular lateral incisors and canines; occurrence in the posterior region is rare $[9,10]$.

The frequent occurrence of dental anomalies following PFT were reported in both related and unrelated regions in previous studies [9-11]. Anomalies in the succeeding permanent dentition include supernumerary and congenitally missing teeth, repeated double-tooth formation, and peg-shaped permanent incisors [12, 13]. Because these anomalies require clinically demanding treatment, careful follow-up of patients with PFT is important. The aim of this study was to investigate the characteristics of PFT and their effect on permanent dentition in a group of Turkish children.

\section{Subjects and Methods}

Dental records of 13,450 pediatric patients who attended the Pediatric Dental Clinic in northern Turkey from 2015 to 2017 were reviewed. Forty patients (24 boys and 16 girls; age range 3-10 years) had been diagnosed with PFT and were included in this study. The study was approved by the Human Ethics Committee of the Ondokuz Mayis University, and all procedures were conducted in accordance with the 1975 Helsinki Declaration (as revised in 2008).

Power and sample size estimates were calculated for this study according to the estimate that the proportion of Caucasian patients with PFT was approximately $0.1-1.6 \%[14,15]$. The minimum sample size needed with an error of $0.5 \%$ was:

Sample size $=\left(z^{2} \times p[1-p]\right) / d^{2}=\left(1.96^{2} \times[0.085 \times 0.915]\right) /$ $0.005^{2}=11,951$

where: $z=z$ score (1.96 for a confidence level of 95\%), $p=$ expected proportion (estimated $0.085 \%$ as it belongs to the range of prevalence rates in previous studies where prevalence ranged between 0.1 and $1.6 \%$ in Caucasians), and $d=$ marginal error (we chose $0.5 \%$ in our study). Our sample comprising 40 subjects can therefore be considered statistically representative.

Exclusion criteria were medically compromising diseases and a history of trauma to the primary dentition. Panoramic and periapical radiographs were obtained from each child to help verify the current clinical status and detect other anomalies.

Data regarding PFT occurrence and its effects on permanent dentition (e.g., normal teeth, hypodontia, talon cusps, and peg-
Table 1. The distribution of primary fused teeth with respect to gender, location, occurrence, and type of fusion

$n(\%)$

$\begin{array}{lc}\text { Gender } & \\ \quad \text { Male } & 24(60) \\ \text { Female } & 16(40) \\ \text { Location } & \\ \quad \text { Maxilla } & 8(16) \\ \quad \text { Mandible } & 42(84) \\ \text { Occurrence } & \\ \quad \text { Unilateral } & 34(85) \\ \text { Bilateral } & 6(15) \\ \text { Type, maxilla/mandible } & \\ \text { I } & 4 / 8(24) \\ \text { II } & 4 / 4(16) \\ \text { III } & 2 / 18(40) \\ \text { IV } & 2 / 8(20)\end{array}$

shaped teeth) were recorded. Each primary fused tooth was evaluated according to the morphological classification of Aguiló et al. [16] as follows: type I: bifid crown, single root; type II: large crown, large root; type III: 2 fused crowns, double conical root; and type IV: 2 fused crowns, 2 fused roots.

PFT and associated risks (e.g., periodontal disease, caries, and missing teeth) were explained to parents, written informed consent was obtained, and follow-up examinations were scheduled. Clinical and radiographic records of PFT were evaluated by 2 experienced pediatric dentists (S.T.E. and H.A.) and interobserver variability was low. Descriptive statistics (type of fusion, clinical location, and demographic variables including age and sex), pathology, and the incidence of complications associated with PFT were calculated and recorded.

\section{Results}

Fifty PFT were observed in the 40 patients. The distribution of PFT regarding sex, the location in the dental arch, unilateral/bilateral occurrence, and type of fusion are shown in Table 1. All PFT were located in the anterior region. Fusion of the mandibular lateral incisor and canine accounted for 34 (68\%) PFT, followed by fusion of the mandibular central incisor and lateral incisor in 6 $(12 \%)$. Fusion occurred bilaterally in $6(15 \%)$ patients, in 1 of whom it involved a maxillary left lateral incisor and canine in addition to a bilateral fusion of the mandibular lateral incisors and canines (Fig. 1).

The most frequently occurring fusion was type III, seen in 20 subjects ( $40 \%$ ), followed by types I, IV, and II. The majority of the type III PFT were located in the mandible $(n=18$ [90\%]) (Table 1). Additional dental anoma- 


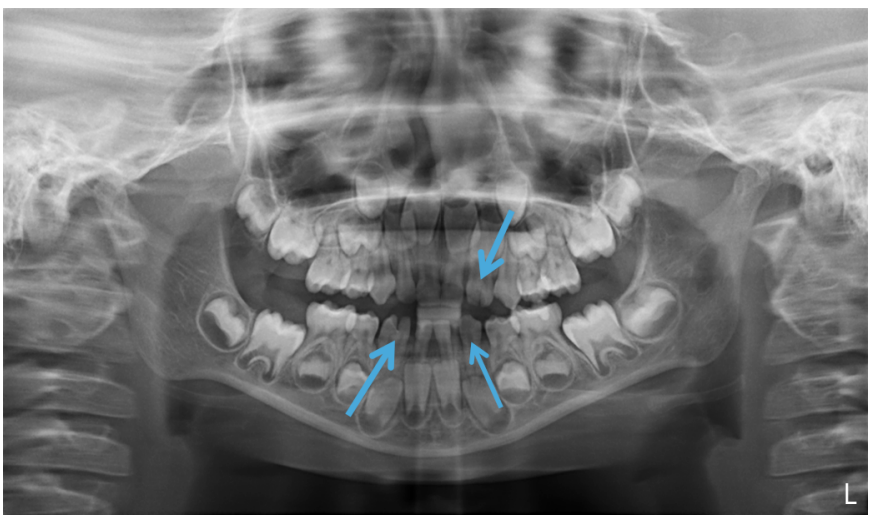

Fig. 1. Panoramic radiograph of a 5 -year-old patient showing 3 primary fused teeth (arrows) at the same time.

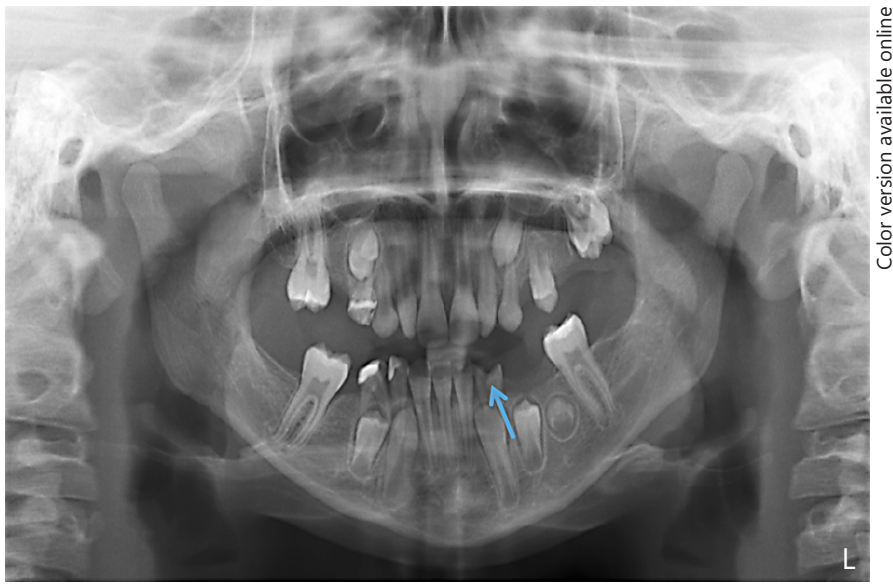

Fig. 2. Panoramic radiograph of a 9-year-old patient with type 3 fusion, showing aplasia of teeth $13,15,17,25,32,37,45$, and 47, and also peg-shaped lateral incisors (arrow).

Table 2. The distribution of 40 dental anomalies according to the type of primary fused teeth

\begin{tabular}{llcrrr}
\hline Anomaly & $\begin{array}{l}\text { Finding in permanent } \\
\text { dentition }\end{array}$ & Type 1 & Type 2 Type 3 & Type 4 & Total \\
\hline Fusion-related tooth aplasia & in a related region & 2 & 2 & 14 & 8 \\
Ectopic eruption & in a related region & - & - & 2 & - \\
Delayed tooth eruption & in a related region & - & - & 4 & - \\
Peg-shaped incisor & in an unrelated region & - & - & 2 & - \\
Talon cusp & in an unrelated region & 2 & - & - & - \\
Multiple tooth aplasia & & - & - & 2 & 2 \\
\hline
\end{tabular}

lies in related or unrelated regions were observed in 34 (85\%) patients. The distribution of dental anomalies by PFT type is shown in Table 2. Fusion-related permanent tooth aplasia was observed in $26(65 \%)$ patients; of these, 4 (10\%) involved the aplasia of multiple teeth. Of the 26 patients with aplasia, 14 (53.8\%), had type III PFT. Cooccurrence of peg-shaped lateral incisors and aplasia of multiple teeth was detected in 2 (5\%) patients (Fig. 2). Delayed permanent tooth eruption was only observed in association with type III PFT $(n=4[10 \%])$. Caries formation was detected at the line of demarcation in 24 (48\%) PFT cases, most frequently in type IV and type III fusion.

\section{Discussion}

In this study, PFT were detected in 40 patients. The most commonly affected teeth were the mandibular lateral incisors and canines, and the most prevalent type was type III. The majority of patients with PFT (85\%) also exhibited other dental anomalies such as tooth aplasia, peg-shaped incisors, talon cusps, and ectopic and delayed eruption in related as well as unrelated areas. The most common complications of PFT were fusionrelated tooth aplasia and caries formation in the affected teeth.

In this study, the finding that fusion of a primary mandibular lateral incisor and canine was the most common is consistent with those of previous studies $[9,11]$. The high incidence of adjacent anterior tooth fusion was attributed to the similar developmental stage and physical proximity of the 2 tooth germs [12]. The finding that $15 \%$ of patients presented with fused teeth bilaterally is higher than the $0.02 \%$ reported previously [2], probably due to the small number of samples in this study.

Type III PFT was the most common form observed in this study whereas Zengin et al. [10] reported that type IV was the most common. This difference could be due to 
advanced root resorption in older children and superpositioning in radiographs.

The $85 \%$ of permanent tooth anomalies observed in this study was higher than the $50 \%$ reported previously [5]. This result could be attributed to differences in sample characteristics that include the location and type predilection of PFT cases. In this study, the most prevalent fusion detected was between the mandibular lateral and canine teeth, and is known to increase the possibility of permanent tooth anomalies. Gellin [13] reported a rate of permanent tooth anomalies of up to $100 \%$ following the fusion of primary lateral and canine teeth. We found aplasia to be the most common dental anomaly after PFT, especially with type III PFT; this is in line with the findings of Aguiló et al. [16].

Caries involvement was more common with type III and IV PFT than with the other types; this is in line with the findings of previous studies $[10,11,16]$. The deep labial and lingual vertical grooves at the site of fusion may be pronounced and difficult to clean, so it is important that patients and their parents are advised about preventive intervention. The application of fissure sealant, for example, may be considered, in order to prevent caries development in deep grooves [17]. While PFT that are free from caries may not require treatment, those with caries should be treated by restoration. When there is pulpal involvement, endodontic treatment should be performed as for a multirooted tooth [10, 18].

\section{Conclusion}

In this study, the most common fusion of primary teeth was that of the mandibular lateral incisors and canines, and the most common type was type III. Most of the PFT had anomalies of the permanent dentition, the most common being tooth aplasia. Caries formation was also common, especially in cases of type III and type IV fusion.

\section{Disclosure Statement}

There are no conflicts of interest.

\section{References}

1 Chunawalla YK, Zingade SS, Nadeem Ahmed BM: Pulp therapy in maxillary fused primary central and lateral incisor: a case report. Int J Clin Dent Sci 2011;2:22-24.

2 Duncan WK, Helpin ML: Bilateral fusion and gemination: a literature analysis and case report. Oral Surg Oral Med Oral Pathol 1987; 64:82-87.

3 Clayyton JM: Congenital dental anomalies occurring in 3,557 children. J Dent Child 1956;23:206-208

4 Pereira AJA, Fidel RAS, Fidel RS: Maxillary lateral incisor with two root canals: fusion, gemination or dens invaginatus. Braz Dent J 2000;11:141-146.

5 Brook AH, Winter GB: Double teeth. A retrospective study of "geminated" and "fused" teeth in children. Br Dent J 1970;129:123130 .

6 Levitas TC: Gemination, Fusion, twinning and concrescence. ASDC J Dent Child 1965; 32:93-100.
7 Magnusson TE: Hypodontia, hyperodontia, and double formation of primary teeth in Iceland. An epidemiological study. Acta Odontol Scand 1984;43:137-139.

8 Hagman FT: Anomalies of form and number, fused primary teeth, a correlation of the dentitions. ASDC J Dent Child 1988;55:359-361.

9 Tsujino K, Yonezu T, Shintani S: Effects of different combinations of fused primary teeth on eruption of the permanent successors. Pediatr Dent 2013;35:64-67.

10 Zengin AZ, Celenk P, Gunduz K, et al: Primary double teeth and their effect on permanent successors. Eur J Paediatr Dent 2014;15: 309-312.

$11 \mathrm{Wu}$ CW, Lin YT, Lin YT: Double primary teeth in children under 17 years old and their correlation with permanent successors. Change Gung Med J 2010;33:188-193.

12 Yeun SWH, Chan JCY, Wei SHY: Double primary teeth and their relationship with the permanent successors: a radiographic study of 376 cases. Pediatr Dent 1987;9:42-52.

13 Gellin ME: The distribution of anomalies of primary anterior teeth and their effect on the permanent successors. Dent Clin North Am 1984;28:69-80.
14 Ravn JJ: Aplasia, supernumerary teeth and fused teeth in the primary dentition. An epidemiologic study. Scand J Dent Res 1971;79: $1-6$.

15 Boyne PJ: Gemination; report of two cases. J Am Dent Assoc 1955;50:194.

16 Aguiló L, Gandia JL, Cibrian R, et al: Primary double teeth. A retrospective clinical study of their morphological characteristics and associated anomalies. Int J Paediatr Dent 1999;9: 175-183.

17 Memarpour M, Fakhraei E, Dadaein S, et al: Efficacy of fluoride varnish and casein phosphopeptide-amorphous calcium phosphate for remineralization of primary teeth: a randomized clinical trial. Med Princ Pract 2015; 24:231-237.

18 Santos LM, Forte FD, Rocha MJ: Pulp therapy in a maxillary fused primary central incisor report of a case. Int J Pediatr Dent 2003;13: 274-278. 